\title{
PRÁXIS ENUNCIATIVA E PRÁTICA INTERPRETATIVA EM VIDEOGAMES
}

\author{
ENUNCIATIVE PRAXIS AND INTERPRETATIVE \\ PRACTICES IN VIDEOGAMES
}

\author{
Mário Sérgio Teodoro da Silva Junior ${ }^{1}$
}

\begin{abstract}
RESUMO: No presente artigo, nos propomos a apresentar uma abordagem analítica de videogames contemporâneos que leve em conta sua dimensão prática, compreendendoos como objetos de linguagem posta em uso enquanto práxis enunciativa. Por ser uma mídia interativa, o videogame implica a atitude responsiva do jogador, instaurando ainda uma práxis interpretativa, localizada em uma estrutura prática complexa, que parte da enunciação e da destinação de tarefas a serem cumpridas, o seu cumprimento e a avaliação da performance, de maneira recursiva e indefinida, tendo em vista o percurso de treinamento do jogador e a oferta de segundas chances. Para apresentar essa estrutura, recorremos à semiótica discursiva nos desdobramentos propostos por Jacques Fontanille, autor expoente da área que trata das interfaces da teoria com a antropologia, a sociologia e a fenomenologia a fim de contribuir para uma semiótica da cultura.
\end{abstract}

PALAVRAS-CHAVE: Videogames. Semiótica. Práxis. Enunciação.

\begin{abstract}
We address an analytical approach of video games in order to take into account its practical dimension, considering them as language objects put in action as an enunciative praxis. Given that video game are an interactive media, we must infer the response of a player, therefore establishing yet an interpretative praxis that composes a complex structure for the major practice. The practice starts with an enunciation that address the player with tasks to complete, then houses the development of those tasks and the performance evaluation. To demonstrate such structure, we recur to Jacques Fontanille's proposes relating to Semiotics of Culture, as a notable author in Discursive Semiotics' field and his interfaces with Anthropology, Sociology and Phenomenology. KEYWORDS: Video games. Semiotics. Praxis. Enunciation.
\end{abstract}

\section{Introdução: a análise das práticas e os níveis de pertinência da experiência semiótica}

A fim de analisar videogames à luz da teoria semiótica discursiva, observada em seus desdobramentos contemporâneos, desde o gesto fundador de Greimas, lançamos mão de conceitos e posicionamentos metodológicos para descrever a prática de jogar como um objeto de linguagem, isto é, grandeza constituída por uma estrutura discursiva, que engloba a sintagmatização, um paradigma pertinente operatório atualizado por um

\footnotetext{
${ }^{1}$ Universidade Estadual Paulista (UNESP). Mestre em Linguística e Língua Portuguesa. Membro do GPS - Grupo de Pesquisa em Semiótica da UNESP. Contato: mario.teodoro@unesp.br
} 
jogador e um horizonte sociohistórico capaz de reger e prever os diversos usos possíveis de um jogo.

Para tanto, devemos discriminar o conjunto significante que analisamos aqui: um processo interativo que textualiza vídeo na tela, operando por meio de aparatos táteis sobre um fundo ideológico e uma profundidade cultural própria aos videogames. Essas dimensões são distintas, pois suscitam substancialidades diferentes: som, luz, espaço tridimensional, canais perceptivos, cognição, tempo, ideias, identidade, etc. Tais instâncias podem ser interpretadas a partir de Jacques Fontanille (2008a, 2008b, 2010), que as aloca naquilo já chamado de percurso gerativo da expressão.

Não se trata de um percurso gerativo do plano da expressão tal como se configura o percurso gerativo do plano do conteúdo, consagrado na base greimasiana da semiótica, correspondente ao texto enquanto globalidade material. É, na realidade, um percurso das expressões distintas de uma mesma experiência, não se restringindo ao texto verbal, visual, sonoro, etc., mas ao conjunto de grandezas significantes.

No caso dos videogames, o seu texto, sua grandeza material audiovisual, não navega em abstração, mas é resultado de uma cadeia complexa, localizada no tecido da sociedade e da História, mobilizada por sujeitos igualmente sociohistóricos e responsável por uma práxis enunciativa e outra práxis interpretativa que culminam em um processo de textualização. O trabalho de Fontanille reserva a cada substancialidade específica um nível pertinente, segundo o modelo (ver Figura 1)

Figura 1: percurso gerativo da expressão da experiência semiótica.

\begin{tabular}{|c|c|}
\hline $\begin{array}{c}\text { tipo de } \\
\text { experiência }\end{array}$ & Nível da expressão \\
\hline comportamento & FORMAS DE VIDA \\
\hline conjuntura & ESTRATÉGIAS \\
\hline nrática & Cenas \\
\hline pranca & PREDICATIVAS \\
\hline corporeidade & OBJETOS-SUPORTE \\
\hline interpretação & $\begin{array}{c}\text { TEXTOS- } \\
\text { ENUNCIADOS }\end{array}$ \\
\hline figuratividade & FIGURAS-SIGNO \\
\hline
\end{tabular}

Fonte: formulado a partir de Fontanille (2008b, p.20). 
No caso dos videogames, a extensão das expressões da experiência recobre elementos imbricados na seguinte cadeia:

1. a expressão audiovisual do texto-enunciado, em uma tela de televisão, de computador ou de celular;

2. os aparatos físicos palpáveis que garantem tanto a reprodução desse jogo (a tela), como objeto-suporte, quanto a interação do sujeito por meio de controles (o joystick, o mouse, o teclado), como instrumento de textualização;

3. a operação das ações e atos interpretativos, que compõem uma cena de predicados práticos;

4. o porquê jogar, a estratégica do jogador, que se explica no tecido sociohistórico e psicossocial;

5. e, por fim, os comportamentos estratégicos desse jogador enquanto configurações de uma maneira de ser, um ethos ou forma de vida.

O texto é o nível referido, na metalinguagem de Fontanille, como texto-enunciado, responsável pela experiência de interpretação, conduzida por um sujeito "leitor". Concebê-lo como texto já enunciado localiza a enunciação de maneira transversal a outras experiências. Não obstante, lidamos com a prática da enunciação em videogames, ligada à interpretação-interação do jogador, como um contínuo cujo fim é ocupado por um textoenunciado. A prática, por sua vez, ocupa o nível das cenas predicativas, em que tomam lugar as operações, sejam as de enunciação, as de interpretação, as de manuseio, etc., cuja experiência é pragmática. Entre texto e prática há uma mediação realizada pela superfície na qual um texto encontra-se inscrito, o objeto-suporte, manipulado pelos actantes de uma cena predicativa e instaurador de coerções materiais para a existência da expressão linguística, plástica, musical, etc. A experiência que tais suportes fornecem aos sujeitos da cena é a de corporeidade, de materialidade.

As cenas predicativas possuem uma finalidade que, frente a uma globalidade de outras práticas, demonstram uma estratégia de conjunto. A estratégia é o nível que permite a experiência de conjuntura ao sujeito. A conjuntura alimentada por essa estratégia, por sua vez, culmina em uma experiência de comportamento, responsável pela criação de identidades localizáveis na cultura, denominadas formas de vida. Por fim, como partimos do nível dos textos-enunciados, deixamos de apontar o nível inferior, em que as figuras de um texto, na medida em que possuem alguma autonomia, configuram símbolos nutridos de significação suficiente para denominar o nível das figuras-signo, cuja experiência é a própria figuratividade.

Tendo em vista esse panorama da pesquisa em semiótica atual, analisamos, no presente artigo, o momento em que um sujeito se converte em operador, responde às instruções e reage às avaliações dos comandos que ele imprime sobre um controle. 
Falamos, aqui, de videogames contemporâneos jogáveis em consoles como o PlayStation e o Xbox, desdobramentos históricos do design de games desenvolvidos desde os anos 1980 e 1990 como, por exemplo, o Super Nintendo e o popular Super Mario World (1990). Nesses tipos de jogos, o jogador da cena predicativa controla uma personagem, em um mundo fictício e tem seu desempenho sob constante avaliação.

\section{Práxis enunciativa}

Essas avaliações já estão comprimidas na forma de possibilidades figurativas na mídia do jogo. A atitude que comprime essas possibilidades figurativas na mídia do jogo é uma enunciação equivalente à produção, regida, portanto, por uma práxis enunciativa, pela colocação da linguagem em um texto, mas que não é integral, e sim partitivo, porque se destina à complementação mediante as atitudes operativas do jogador, que configuram outra práxis, posta na estrutura recursiva da interação.

Como essas atitudes provêm de uma interpretação, é possível alocar simetricamente uma práxis interpretativa. Assim como a práxis enunciativa mobiliza da gramática de uma linguagem aquelas combinações que corroboram um projeto enunciativo, a práxis interpretativa mobiliza combinações da gramática do jogo, isto é, do conjunto de regras e possibilidades operatórias e sua distensão sobre um eixo temporal. O resultado da mobilização também é um produto de linguagem, um enunciado interpretativo.

Dessa maneira, a prática de videogames mostra-se como esse emaranhamento de práxis. Práxis é um conceito que se solidariza à "concepção materialista e realista de linguagem, quer no domínio da sociolinguística (Bourdieu, por exemplo), quer no da lingüística guillaumiana, conhecida como "praxemática"' (FONTANILLE; ZILBERBERG, 2001, p.171). A práxis implica a inserção da atividade linguageira (verbal ou não-verbal) no conjunto das atividades humanas, na extensão do que a semiótica discursiva concebe como mundo natural, isto é, o mundo mesmo da cultura (Cf. GREIMAS; COURTÉS, 2013, p.324)

Uma das hipóteses subjacentes à noção de "práxis" aplicada ao domínio lingüístico, e de que partiremos aqui, é que tendo a língua - e, de maneira geral, a competência dos sujeitos enunciantes - o estatuto de simulacro e de um sistema virtual, a enunciação é uma mediação entre o atualizado (em discurso) e o realizado (no mundo natural). Em suma, a enunciação é uma práxis na exata medida em que dá certo estatuto de realidade - a ser definido - aos produtos de linguagem: a língua se destaca por definição do "mundo natural", mas a práxis enunciativa a reincorpora nele, sem o que os "atos de linguagem" não teriam qualquer eficácia nesse mundo. Existem de fato dois tipos de atividades 
semióticas, as atividades verbais e as não-verbais, mas ambas estão ligadas a uma só "práxis". (p.172).

Cada um dos predicados da cena prática, isto é, cada segmento coerente em que ações tomam lugar no tempo, configura uma práxis, verbal ou não-verbal, produzindo enunciados audiovisuais imediatamente renderizados na tela ou enunciados táteis, gestuais ou motores, que interpretam, por meio do corpo do jogador, os processos audiovisuais instrutivos, avaliativos, etc.

A instrução é uma práxis enunciativa, porque, como visto, nasce no discurso de produção do videogame, mas não é integral porque ainda carece da interação de um jogador. Tal práxis enunciativa age como destinadora de um enunciado de habilitação, com discurso de manipulação do operador, coagindo como este deve proceder no controle da personagem. O operador, por sua vez, conduz uma práxis operativa, porque atualiza a instrução anteriormente dada a situações em ocorrência, gerando um enunciado interpretativo. Há aí um discurso ao qual o jogador fornece uma resposta operatória, mas a interatividade per se, a disposição desses sujeitos práticos em certo "pé de igualdade", ocorre quando a práxis enunciativa dá a réplica, na forma de enunciados avaliativos, que correspondem a sanções no percurso narrativo do operador, que, em tréplica, é levado a reinterpretar suas próprias ações. Em outras palavras, o jogador deve reinterpretar o mesmo enunciado interpretativo que ele produziu na forma de comandos operatórios. Trata-se de uma segunda práxis interpretativa, recursiva à primeira. Assim, a dinâmica da interação das práxis continua, conforme o andamento temporal do jogo, em sucessivas camadas de interpretação, uma atitude metainterpretativa.

\section{A prática interpretativa}

Fontanille (2008b, p.96) propõe um modelo para a práxis interpretativa tornada cena prática (ver Figura 2), em que quatro instâncias se interdefinem: um actante interpretativo posto em ato toma outra cena predicativa de horizonte referencial para operar uma tradução intersemiótica dessa cena em um novo enunciado, de caráter interpretativo. 
Figura 2: modelo triangular da cena interpretativa.

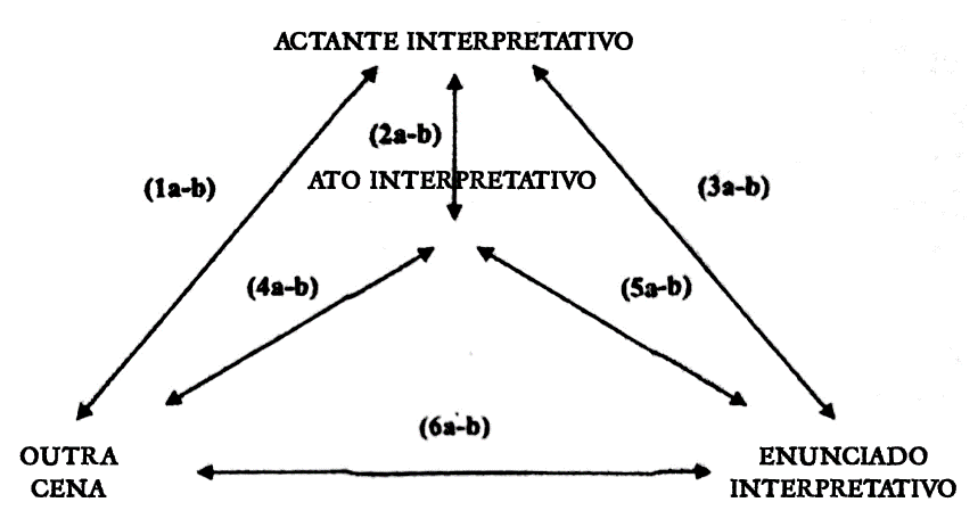

Fonte: traduzido de Fontanille (2008b, p.97)

Sobre o elo estrutural discreto formado entre cada uma das instâncias, o autor aponta:

1 a / O intérprete visa a outra cena, dando-lhe uma representação transponível: ele identifica as variáveis e as tensões instáveis, das quais transporta as inflexões.

$1 \mathrm{~b} /$ A outra cena oferece oportunidades de identificação e confrontação para o intérprete.

2 a / A presença do intérprete, como ator, é necessária para a execução do ato. Sendo esta condição modalizável e seu efeito avaliável, o intérprete assume (ou não) seus atos interpretativos, manifestando assim diferentes graus de responsabilidade.

2 b / O ato interpretativo é atribuível ao intérprete, e esta imputação está ela própria sujeita à modalização existencial do predicado (virtualizado, atualizado, potencializado, realizado), da qual resultam as modalidades da identidade do actante.

3 a / O intérprete se expressa por intermédio do enunciado interpretativo, manifestando sua identidade modal e semântica.

$3 \mathrm{~b} /$ Por outro lado, o enunciado interpretativo tematiza o intérprete, dando a ele uma identidade temática provisória.

4 a / $\mathrm{O}$ ato interpretativo transforma a outra cena, modifica suas condições iniciais e seus equilíbrios internos, seja para transpô-la para outro gênero, seja para transformá-la em outra semiótica-objeto; também executando os ajustamentos espaço-temporais, rítmicos e aspectuais entre a cena da qual ele é centro predicativo e a outra cena.

4 b / A outra cena oferece ao ato interpretativo uma diversidade de componentes entre os quais ele pode operar seleções, focalizações, manipulações mereológicas, até transferências metonímicas (ou, para falar do sonho em Freud, condensações e deslocamentos).

5 a / $\mathrm{O}$ ato interpretativo produz o enunciado interpretativo (que pode ser unimodal ou multimodal), mas, em contrapartida, este último é a condição e o critério para a realização do ato, como actante-objeto.

5 b / Por outro lado, o enunciado manifesta o ato, não só como resultado, mas também como lugar onde seus traços se inscrevem. A relação é, portanto, aqui a remanência do ato em seu enunciado.

6 a / A outra cena é o horizonte referencial a ser transformado; pode incluir um texto-enunciado, com o qual o enunciado interpretativo manterá relações "intertextuais", relações de tradução e reformulação estratégica; também oferece vários outros elementos, especialmente actantes, que podem ser objeto de uma encenação discursiva no enunciado interpretativo. A relação aqui é, portanto, de transposição-apresentação. 
6 b / O enunciado interpretativo adota várias posições estratégicas em relação à outra cena: metassemiótica, conotativa, ficcional, didática, etc.. ${ }^{2}$ (FONTANILLE, 2008b, p.97-98, tradução nossa)

A capacidade metainterpretativa do operador de videogames deve-se, portanto, a declinação do enunciado interpretativo em um predicado posto no horizonte referencial. O passado do jogador no jogo passa a ser objeto de interpretação, retomado nos mesmos parâmetros relacionais que estabelece a "outra cena" com todas as instâncias da prática interpretativa: identificação, confrontação, transposição, ajustamentos espaço-temporais, rítmicos e aspectuais, focalização, transposição, etc. Referindo-se àquilo já posto em ato anteriormente, esse sujeito pode aperfeiçoar seus movimentos operatórios. Logo, o jogo é mais recursivo à medida que o jogador volta seu olhar para seu ato, adaptando-se a ele. Ainda mais adiante, retornamos a essa dinâmica recursiva e autoadaptativa e seu contrário.

\section{A esquematização da cultura}

Entretanto, há uma primeira "outra cena" posta em jogo antes que seja possível a recursividade interpretativa, que suscita uma autoavaliação. Esse primeiro horizonte referencial do ato de estreia do jogador é cultural, e demonstra a integração do nível máximo da cultura no nível das práticas via um processo de esquematização.

21 a / L'interprète vise l'autre scène pour en donner une représentation transposable: il en identifie les variables et les tensions instables, sur lesquelles faire porter les inflexions. $1 \mathrm{~b} /$ L'autre scène offre des opportunités d'identification et de confrontation à l'interprète. 2 a / La présence de l'interprète, en tant qu'actant, est requise pour la réalisation de l'acte. Cette condition étant modalisable, et son effet, évaluable, l'interprète assume (ou pas) ses actes interprétatifs, et manifeste ainsi différents degrés de responsabilité. $2 \mathrm{~b} /$ L'acte interprétatif est imputable à l'interprète, et cette imputation est elle-même soumise à la modalisation existentielle du prédicat (virtualisé, actualisé, potentialisé, réalisé), dont il découle les modalisations factitives de l'identité de l'actant. 3 a / L'interprète s'exprime par l'intermédiaire de l'énoncé interprétatif (il manifeste son identité modale et sémantique). $3 \mathrm{~b} /$ Inversement, l'énoncé interprétatif thématise l'interprète (al lui procure une identité thématique provisoire). 4 a / L'acte interprétatif transforme l'autre scène, en modifie les conditions initiales et les équilibres internes, soit pour la transposer dans un autre genre, soit pour en faire une autre sémiotique-objet il procède également aux ajustements spatiotemporels, rythmiques et aspectuels entre la scène dont il est le centre prédicatif et cette autre scène. $4 \mathrm{~b} /$ L'autre scène offre à l'acte interprétatif une diversité de compo sants parmi lesquels il peut opérer des sélections, des focalisations, des manipulations méréologiques, voire des transferts métonymi ques (où, pour parler comme Freud à propos du rêve, des condensa tions et les déplacements). 5 a / L'acte interprétatif produit l'énoncé interprétatif (qui peut être lui-même un énoncé unimodal ou multimodal), mais en retour, ce dernier est la condition et le critère de réalisation de l'acte, en tant qu'actant-objet. $5 \mathrm{~b}$ I Inversement, l'énoncé manifeste l'acte, non seulement comme son résultat, mais aussi comme le lieu d'inscription de ses traces. La relation est donc ici la rémanence de l'acte dans son énoncé. 6 a / L'autre scène est l'horizon référentiel à transformer; il peut comprendre un texte énoncé, avec lequel l'énoncé interprétatif entretiendra des relations «intertextuelles», des relations de traduction et de reformulation stratégique; elle offre aussi plusieurs autres éléments, notamment des actants, qui peuvent faire l'objet d'une mise en scène discursive dans l'énoncé interprétatif. La relation est donc ici celle de transpositionprésentation. $6 \mathrm{~b} /$ L'énoncé interprétatif adopte à l'égard de l'autre scène des positions stratégiques diverses: méta-sémiotiques, connotatives, fictionnelles, didactiques, etc. 
Fontanille propõe uma sintaxe genérica de acomodação a toda prática, que consiste na resolução “de uma situação inicial de 'falta de sentido' [...] e essa sequência terá a seguinte forma canônica: < falta de sentido - esquematização - regulação adaptação >" (FONTANILLE, 2008b, p.53). A falta de sentido de uma situação em ocorrência é, no processo de acomodação, confrontada a uma situação-tipo, cujo desenvolvimento sintagmático é socialmente reconhecido, esquematizado na cultura e passível de ser aplicado à situação-ocorrência por semelhança. A regulação corresponde à aplicação dessa forma sintagmática eficiente e a adaptação (no original em francês, accommodation $^{3}$ ) designa o conjunto da práxica, englobando tanto seu resultado formal, como a forma correlatada encontrada via esquematização e sua inserção na prática em curso via resolução (FONTANILLE, 2010, p.18). Em outras palavras, o devir de uma prática é o campo configurado pela tensão entre um esquema práxico virtual, esquemático, e uma situação atualizada, a qual a resolução dá uma forma sintagmática eficiente a uma estratégia.

A "falta de sentido" consiste na abertura axiológica máxima, tendo em vista que a prática se encontra em um aspecto incoativo, ainda tomando seu lugar na progressão temporal (FOTANILLE, 2010, p.16), possuindo meramente modo de existência virtual, ainda não atualizado. É a ausência de uma sintaxe intrapráxica eficiente, que se deve vislumbrar no horizonte cultural, de práticas possíveis, de onde os praxemas operatórios serão postos em uso pelo operador.

É possível apontar a integração desses praxemas ao nível dos objetos. Tanto no controle do Super Nintendo, de 1990, como no controle do Xbox One, de 2013, por exemplo, há pelo menos um botão direcional (ver Figura 3), cujas projeções para cima, para baixo, para a esquerda e para a direita criam coerções do movimento operatório, configurando um praxema direcional que se textualiza no movimento da personagem para a mesma direção ${ }^{4}$.

\footnotetext{
${ }^{3}$ Optamos por traduzir accommodation por acomodação e não por adaptação, conforme apresentado na obra traduzida de Fontanille (2008b). Entendemos que o ponto-chave da argumentação do autor é que a prática é um processo de sucessivas acomodações da forma eficiente do esquema à situação-ocorrência, com vistas a um horizonte estratégico. Trata-se de uma adaptação, conforme o sentido em português do termo, mas, quando essa acomodação deixa de visar a um horizonte alhures, das práticas afins identificadas na cultura, a adaptação não é mais um processo de subjugação da ocorrência ao esquema, mas, ao contrário, um ajustamento contínuo da ocorrência a seu próprio curso, com a consequente atomização da estratégia social e individualização do ato. Os videogames fornecem justamente um tipo de experiência individual, em que a ocorrência e o esquema encontram-se em certo pé de igualdade; o esquema é acomodado, não mais alvo da adaptação.

4 No caso do Xbox One, há três botões direcionais, dos quais aquele em formato de cruz é obsoleto em diversos jogos atuais, que contam com dois, em formato de haste manipulável para as direções em $360^{\circ}$; o
} 
Figura 3: controles do Super Nintendo e do Xbox One, respectivamente.
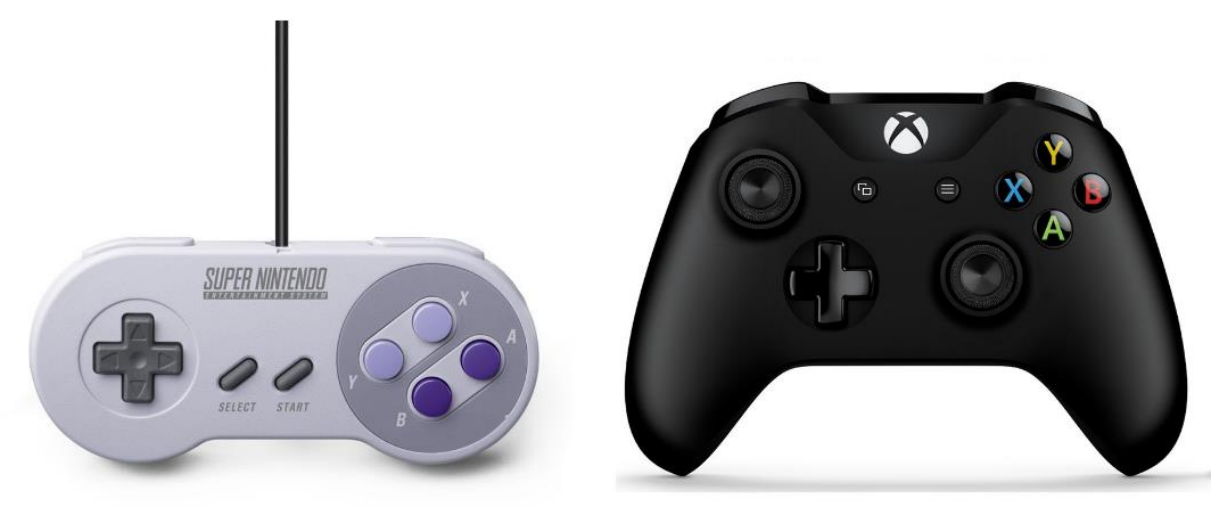

Esses são apenas indícios da esquematização da prática de jogar, que pouco respondem às inquietações da pesquisa. Seria de caráter meramente especulativo colocarmos questões basais a respeito de como um sujeito humano consegue operar videogames. Essas colocações teóricas não poderiam se satisfazer com explicações referentes à experiência física humana pontual, do tipo "direita/esquerda", ou referente aos cinco sentidos isolados, enquanto canais perceptivos, mas, ao contrário, devem buscar estruturação na função simbólica humana, representável, por exemplo, em dois blocos sensoriais e sensório-motores, como os da mão-ferramenta e da face-linguagem, que permitem a manipulação do mundo tátil e sua exploração e a produção de linguagem verbal e gestual a percepção gustativa (LEROI-GOURHAN apud FONTANILLE, 2016, p.76). Entretanto, considerar o conjunto mão-ferramenta como processo físico autônomo para a operação prática dos videogames não basta. $\mathrm{O}$ uso da mão-ferramenta é culturalmente comprometido, e não uma qualidade autônoma per se: "a percepção não é, portanto, uma simples inspeção das coisas: é uma antecipação exercida pelo corpo" (MERLEAU-PONTY, 2016, p.100). A qualidade não está nem no corpo de quem percebe, nem no objeto percebido, mas no tecido mesmo da cultura que sedia toda atividade sensível.

Assim, "falta de sentido" e "esquematização" devem ser compreendidos como camadas da atividade perceptiva que condicionam o surgimento do percurso propriamente dito, cuja forma é a da acomodação dos valores e narrativas cristalizadas na cultura ao ato. Essa práxica de acomodação só pode tomar lugar quando as diretrizes

mais à esquerda responsável pelo movimento da personagem e o mais à direita, pelo campo de visão do jogador. 
operatórias a serem adotadas por um jogador já foram presentificadas na atividade cognitiva desse sujeito.

Trata-se de uma condição à prática: a assunção do papel de jogador, papel proveniente da cultura, sob a forma de vida reconhecível. Lidamos, aqui, com um processo de integração descendente: a prática faz-se integrante do texto, a forma de vida faz-se integrante da prática.

\begin{abstract}
A forma de vida, na perspectiva do projeto greimasiano, constitui-se em um nível de descrição das gestões dos valores culturais identitários próprios um do outro. Portanto, a forma de vida não é jamais natural, mas uma construção cultural individual e coletiva que se encarrega do sentido da vida [...]. (NASCIMENTO, 2014, p.42)
\end{abstract}

Assim, essa assunção dos conhecimentos culturais que possui um jogador, habilitação anterior à prática do jogo, mas também presentificada nos objetos-suportes em coerções que direcionam a interpretação a situações-tipo específicas, revelam a ligação de um sujeito cognoscente à cultura que o constitui, pautando-se na congruência desses valores; quando não congruentes, é que a autoadaptação pode tomar lugar.

\begin{abstract}
A teoria da semiosfera proposta do I. Lotman poderia acolher tal observação. O centro da semiosfera seria, nesse sentido, definido como o topos cultural em que se concentra a maioria das taxionomias superponíveis: seria constituído, então, de microssemióticas homologadas e altamente correlacionadas. A periferia da semiosfera - lugar de trocas com as culturas vizinhas no espaço, ou próximas no tempo, lugar de instabilidade e fonte dos remanejamentos da semiosfera - seria constituída por taxionomias de frágil correspondência. Ali onde a cultura como um todo - o sujeito da enunciação coletivo - não promove a congruência dos recortes culturais, a iniciativa dos sujeitos individuais e as influências periféricas podem ocorrer livremente. (ZILBERBERG; FONTANILLE, 2001, p.192).
\end{abstract}

Portanto, o operador de videogames só pode ser tomado na análise enquanto interface prática do jogador, do sujeito competente na cultura, devidamente motivado a jogar e que não precisa, portanto, alinhar sua prática à estratégia a posteriori de sua colocação em cena, pois sua ligação ao esquema práxico já é efetiva.

Sobre essa profundidade cultural, vale citar as tentativas de compreensão do videogame que desenvolvem justamente essa vocação antropológica de catalogação dos jogos na História humana, propondo consequentes estruturas para a leitura analítica desse objeto. Nomes como o de Roger Callois (1961), por exemplo, exploram uma tipologia dos jogos - aqueles destinados à competição, aqueles regidos pelo acaso, os que contam com objetivos lúdicos ou aqueles cuja finalidade é o inebriamento do jogador —, e ainda como o de Jasper Juul (2005), que se vale da articulação entre real e ficcional como parâmetros de análise da interatividade em games. 
Optamos por centrar-nos na abordagem discursiva, pois vemos que o que Callois aponta é apresentado também por Landowski, na exploração de regimes de interação, não restritos ao universo dos jogos, aplicáveis à profundeza do sentido gerativo do comportamento humano, articuláveis entre si "segundo uma lógica que não deve nada à psicologia, mas procede de uma organização estrutural e imanente" (LANDOWSKI, 2014, p.66-67). Já Juul refere-se àquilo já discutido aqui sob a forma de níveis de pertinência e processos de integração. Na realidade, essa problemática interdisciplinar, já trazida à luz do diálogo com a semiótica discursiva por Ângelo (2015) e Ernica (2019), e apenas sublinhada por nós, é relativa ao choque de perspectivas mais atidas à lógica e aos processos subjetivos de significação, centrados no Eu do sujeito, no campo de presença e na imanência, e outras, atidas à universalização, centradas no objeto exterior à percepção e em suas qualidades. Não obstante, Ernica aponta:

\begin{abstract}
uma insuficiência reconhecida nas diversas epistemologias vigentes em ludologia no que diz respeito à análise de um problema que se torna cada vez mais explícito no mundo dos jogos digitais: o fato de que a variedade observada na comunidade de jogadores gera conflitos com consequências sérias que extrapolam os limites do que se considera jogo - estruturalmente falando - e demonstra que a apropriação livre do lúdico - como definida pela teoria do jogar - não funciona de modo universal. Essa insuficiência deriva justamente do caráter universalizante dessas teorizações, cujas bases datam de séculos antes e de conceitos de Universalidade hoje em dia questionáveis. (ERNICA, 2019, p.146, grifo nosso).
\end{abstract}

Portanto, a cultura não é um nível descartado na análise da prática, mas configurado pela integração descendente, em que a estratégia está integrada à cena predicativa. Ao mesmo tempo, não basta a compreensão cultural para discriminar o andamento interno de uma cena, segundo seus componentes sintáticos e semânticos; ler a prática pela visão da cultura, de maneira ascendente, desdobrando-a, é negar-lhe sua pertinência e tomá-la como figura sintética, devidamente acomodada.

Semanticamente, essa estratégia de jogar videogames é constitutiva dos percursos de vida dos sujeitos inseridos em sociedades marcadas por aparatos digitais, podendo satisfazer tanto a estratégia da competição de habilidades físicas e mentais ou de êxtase, conforme posto por Callois, ou desenvolver uma experiência de entretenimento, mediante a ênfase dada à ficção, em detrimento da competição. Podemos desdobrar essas estratégias com mais propriedade ao falar da textualização dessa prática, pois no enunciado audiovisual encontramos os contrastes de focalização sobre, por exemplo, a exploração de um universo ficcional ou sobre o teste de habilidades da personagem controlada. 


\section{Práxis e inovação}

Esses valores culturais, sincretizados a formas operatórias, localizam-se estabilizados em um horizonte nitidamente e intensamente reconhecido pelos diversos jogadores sujeitos às práticas de jogo, já que se trata da maneira validada e certificada por uma série de outros sujeitos sociais ao longo da História. São praxemas de alta extensão, porque difusos, e de alta intensidade, porque reconhecidos, a tal ponto que o estatuto universal adquirido descarta as próprias práxis mais remotas que os fundaram, isolandoos em uma zona prática descolada (ver Figura 4) (Cf. FONTANILLE; ZILBERBERG, 2001, p.196).

Figura 4: o esquema da práxis.

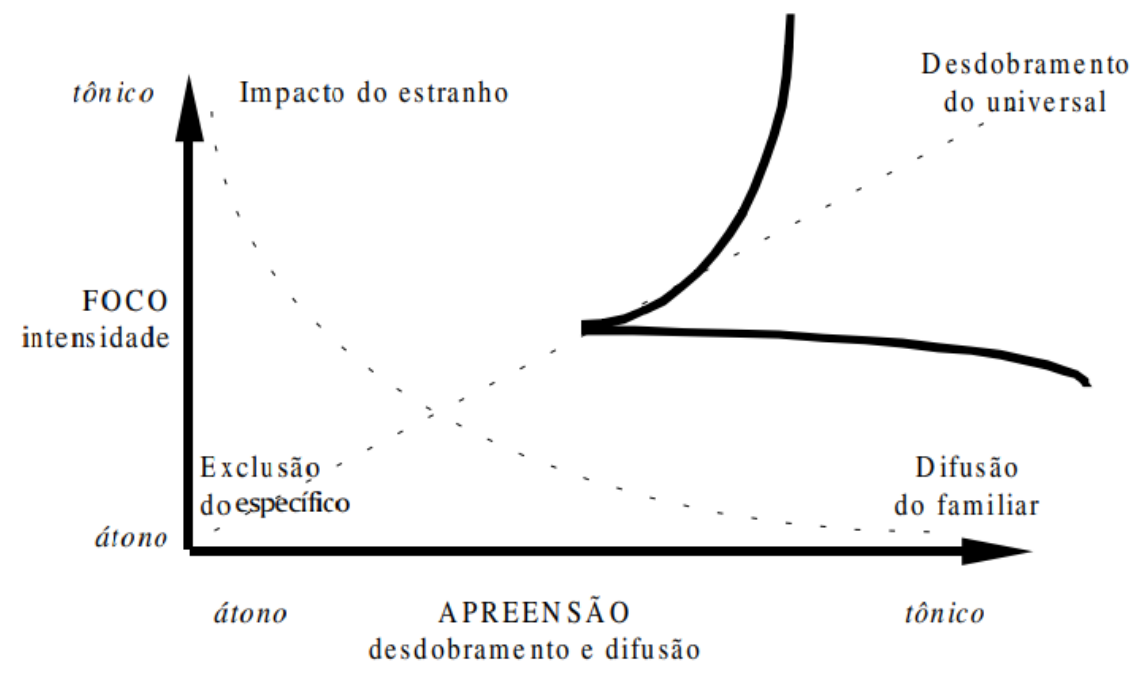

Fonte: extraído de Fontanille e Zilberberg (2001, p.196).

Assim, um jogo só pode se indicar a partir dessa zona universal, e, ao longo de seu desenvolvimento, negá-la, irrompendo novas formas operatórias, sejam destinadas ao jogador ou forjadas pelo próprio operador em atos inovadores. O quão mais um instrutor for mais atido a tais praxemas esquematizados, mais rápido o jogador aplica a resolução, atualizando esses conhecimentos que pouco dizem respeito a um jogo específico. Por outro lado, o quão mais inovador for o instrutor na atualização dos praxemas, mais inovador também deverá ser o jogador.

Na retórica de Juul (2005), nome de relevo nos estudos de videogame, fala-se da ficcionalidade implicada, naquilo que o autor concebe como a semiótica-objeto do jogo, por uma realidade do uso, feito presente na coerção de um conjunto de regras. Ficção e realidade estariam colocadas na estrutura na semiótica-objeto concebida pelo autor, que 
retificamos aqui como uma distinção contemplada pela descrição pertinente de um nível do texto-enunciado, em que a figuratividade estabelece, em embreagens enuncivas, a ficcionalidade, e de um nível da cena predicativa, em que a constante debreagem operativa lida com a conversão do conjunto de regras esquematizadas em regras atualizadas pelo discurso instrutivo e, finalmente, em regras atualizadas pela operação. Do ponto de vista do real, o conjunto de regras é apresentado seguindo princípios de emergência (um conjunto básico de controles instruído) e de progressão (a complexificação por extensidade ou intensidade da operação dos controles básicos). Do ponto de vista do ficcional, o conjunto de regras é engajado em dinâmicas do mundo ficcional e, por isso, negociável em um uso "original” que o jogador possa fazer dele.

A oposição entre o uso implicativo das regras ou o uso original já está traduzido, de alguma maneira, para a semiótica discursiva aqui: é implicativa a adoção e assunção imediata de praxemas operativos pelo narrador-instrutor e pelo operador, a partir da observação de um horizonte social, presentificado nos objetos, que, ao sinalizarem esquerda e direita, implicam o controle da personagem para a esquerda e para a direita; por sua vez, equivale a um uso original, que chamaremos concessivo, aquele que suspende a esquematização pela adoção de uma outra prática, externa e virtual.

Nesse caso, a adoção de um esquema dá lugar, na atenuação de uma perspectiva heteroadptativa, a uma perspectiva autoadaptativa, da prática que se esquematiza a si própria em um movimento prospectivo, projetando para si um esquema capaz de produzir a acomodação eficiente. Assim, "o curso das práticas se descola entre uma pressão reguladora externa (a programação) e uma pressão reguladora interna (o ajustamento), entre a regulação a priori e a regulação em tempo real, vista a posteriori." (FONTANILLE, 2010, p.17, tradução nossa) ${ }^{5}$.

Programação e ajustamento advêm da metalinguagem de Eric Landowski (2014), ao propor uma disposição complementar para diferentes regimes de interação, como aprofundamento da semiótica narrativa greimasiana, criticada pelo autor pela atenção majoritária dada a percursos narrativos do tipo da "programação", em que o actantesujeito desenvolve suas ações regulando-as com base em valores implicativos, a priori do ato, programando sua performance sobre a certeza das consequências futuras. Mas também é mérito da semiótica do período greimasiano o trânsito à semiótica das paixões,

5 Le cours des pratiques se déploie entre une pression régulatrice externe (la programmation) et une pression régulatrice interne (l'ajustement), entre le réglage a priori et le réglage en temps réel, voire a posteriori. 
que explora não ações programáveis, mas ações dependentes da subjetividade flutuante do actante visado, de sua afetividade e de seus valores pessoais. Assim, a "manipulação" complementa a "programação", ambos instituindo o liame desses dois regimes interativos, o do sujeito sobre o mundo programável, objetivo, e o do sujeito sobre o outro, subjetivo, constituindo aquilo que compreendemos, particularmente, como uma dêixis do sujeito tonificado em sua ação unilateral, da centralidade do "Eu".

Por outro lado, se a ação não é unilateral, ela não pode se firmar sobre uma axiologia da subjetividade ou da objetividade, senão sobre um devir axiológico construído no contato sensível entre dois sujeitos sencientes, cuja análise da performance só pode ser obtida a posteriori do ato. $\mathrm{O}$ sujeito atenua-se frente à centralidade do contato no regime do "ajustamento". Por fim, nessa nova dêixis da centralidade daquilo que é "nãoEu", é possível que o sujeito sofra a ação não de outros, com os quais uma estratégia ainda poderia ser forjada, mas do próprio azar, esvaziado de estratégia e de sentido, no regime do "acidente" (ver Figura 5). Logo, o uso "original" e a implicação do universo real de Juul são, na verdade, uma tensão, não entre a cena predicativa e o enunciado do texto audiovisual, mas constitutiva da relação do sujeito e o horizonte social, que, na proposta hjelmsleviana, é uma tensão entre o uso e o esquema, que recupera a dicotomia saussuriana entre fala e língua (GREIMAS; COURTÉS, 2013, p.). Trata-se, na essência, de um problema de linguagem genérico e, portanto, de textualização; retornamos ao ato de linguagem, à práxis. 
Figura 5: regimes de interação, regimes de sentido e regimes de risco.

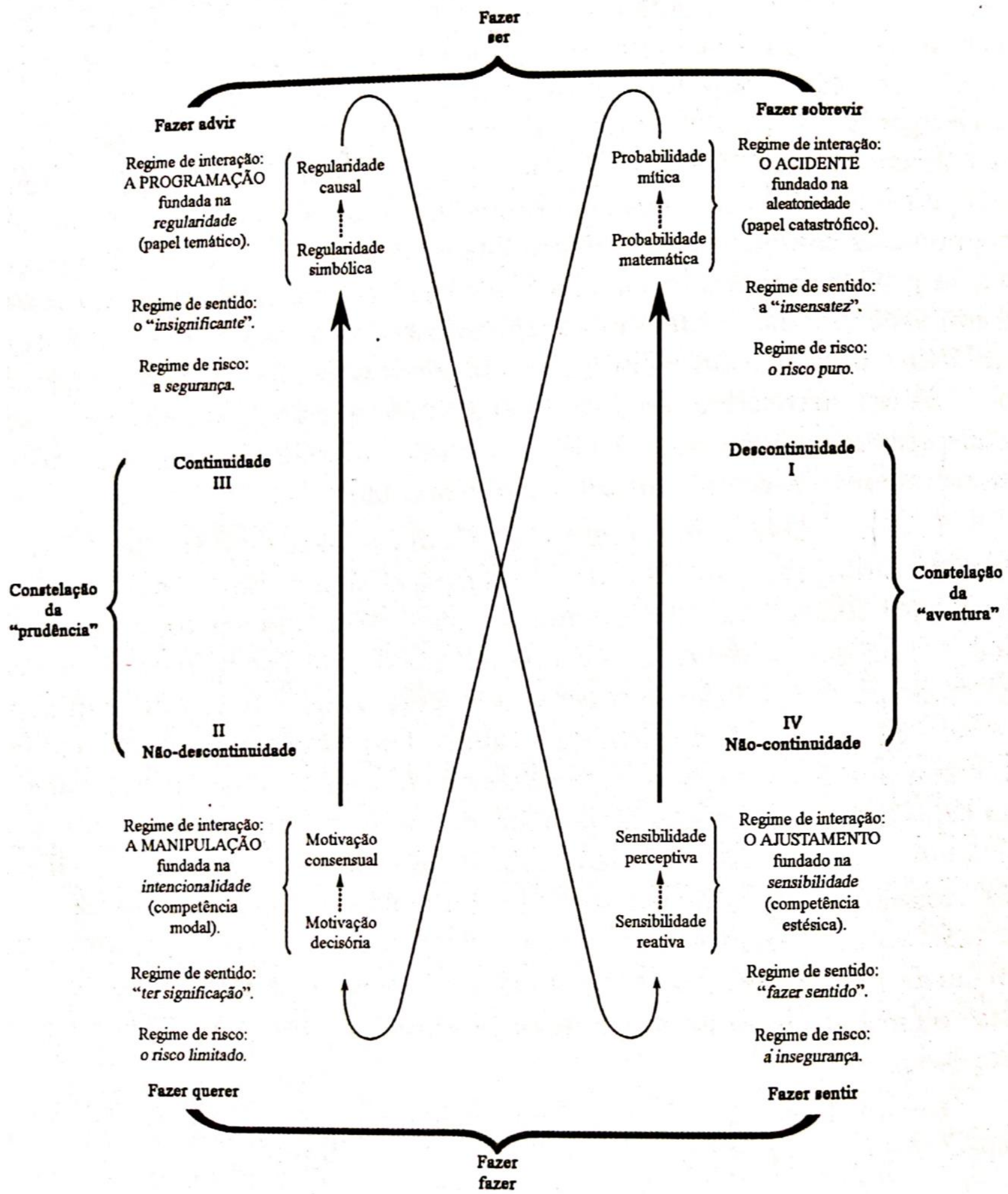

Fonte: extraído de Landowski (2014, p.80)

Cabe observar que a congruência da forma de vida do jogador já pressupõe a passagem à autoadaptação; o uso "original”, o "jogo de cintura" do operador, situações- 
ocorrência de difícil resolução por uma simples transposição da situação-tipo, etc., são eventos esperados, também universalizados na zona difusa e intensa do gráfico do esquema da práxis. A emergência da operação autoadaptativa é cara à experiência dos videogames, de tal maneira que um jogo implicativo poderia ser avaliado como ineficaz enquanto jogo, pois não faria seu operador se destacar por uma atitude autônoma.

É esperado que o operador recorra a interpretações e resoluções menos óbvias dos percalços que lhe são apresentados na tela, que ele reconheça um novo esquema nas soluções dadas aos desafios, deixando de proceder apenas com uma práxis interpretativa programada pela instrução que lhe é fornecida no início ou do horizonte cultural, mas instaurando ainda outra práxis interpretativa, que prestigia os próprios enunciados interpretativos que ele produziu e que, por falharem, cobram a autoadaptatividade, o

ajustamento somático. É essa interpretação em segundo grau, a metainterpretação, que não limita o videogame a uma simples tradução instantânea de instrução em movimentos, mas uma prática interativa complexa.

\section{Considerações finais}

Pudemos observar como enunciação garante, por ser uma práxis esquematizada socialmente, a apresentação de uma narratividade prática canônica, cuja eficácia pode ser revogada, por exemplo, pela suspensão da doação de competências pragmáticas e/ou cognitivas. Essas competências devem ser doadas a priori à ação do jogador, na forma de poderes da personagem e instruções sobre os procedimentos a tomar. Suspendidas, o jogador passa a autoadaptatividade e à observação e ajustamento do ato. Operado o ajustamento, o jogador devolve ao projeto enunciativo uma sequência prática textualizada, potencializada a partir de então na memória do jogo específico, passível também de ser confrontada novamente pelo jogador como solução satisfatória a novos estágios narrativos ou precária, lançando-o mais uma vez a uma prática autoadaptativa. O condicionamento corporal obtido a partir da autoadaptatividade retorna ao horizonte de operações esquematizadas como um conjunto de competências, mas conquistadas $a$ posteriori ao ato.

A partir daquilo que discutimos até aqui, o que resta é descrever o sincretismo actancial que ocorre entre o operador da prática e as personagens que existem no universo fictício discursivizado pelo texto audiovisual. Tal situação já foi descrita, vale citar, em trabalhos de Souza Junior (Cf. SOUZA JUNIOR, 2009, 2015, SOUZA JUNIOR; MANCINI, 2015). Esse sincretismo parece ser o liame entre a sintaxe prática e o tecido 
ideológico da cultura, porque as personagens e seus percursos próprios figurativizam, encarnam, valores; é o enunciado que dá corpo a uma axiologia selecionada enunciativamente.

Assim, é no contato da prática de jogar com o texto formado nos processos enunciativos e interpretativos que está a contiguidade entre a cena predicativa em que o jogador opera o game e o texto que o televisor exibe, simultaneamente. Essas duas dimensões, aquela carnal e viva no tecido social, e esta última eletrônica e expressa por luz e som, compõem um mesmo conjunto significante porque os sujeitos narrativos que existem em cada uma confundem-se em um mesmo percurso. Essa é uma maneira simples de abordar o sincretismo actancial. A enunciação, como práxis, é o liame entre o enunciado ficcional e a prática, porque dá ao operador a posição de enunciatário, responsivo ao videogame com seu próprio fazer interpretativo, e dá a esse enunciatário materialidade, como receptor das instruções e das sanções vistas na tela.

Por fim, para poder dar melhor acabamento à discussão que trouxemos, além de descrever sincretismo, seria necessário considerar a comunhão narrativa desses sujeitos sob a condição de uma simultaneidade do andamento, da progressão temporal e do ritmo dessa progressão. Esse andamento se traduz em aspecto, em duração, velocidade e prospecção, que, na cena predicativa, diz respeito à memória do operador, à passagem da programação da ação, baseada na heteroadaptatividade à instrução e ao horizonte de expectativas culturais, ao ajustamento autoadaptativo, também interpretado no horizonte cultural, esquemático, mas sentido no momento presente e tomado reflexivamente. No texto-enunciado, enquanto possibilidades audiovisuais que textualizam esse andamento prático, produzidas em uma práxis enunciativa que recobre a instrução e a sanção do operador, o andamento está regido pelo projeto enunciativo, sobretudo nas combinações feitas no percurso do jogador e da personagem.

\section{Referências}

ANGELO, José Romero Cardozo. Análise semiótica de videogames: uma aposta na interdisciplinaridade. Dissertação de Mestrado. Programa de Pós-Graduação em Estudos de Linguagem (UFF), 2015.

CAILLOIS, Roger. Man, play and games. Urbana; Champaing: University of Illinois Press, 1961. 
ERNICA, Renato Razzino. Uma perspectiva intercultural sobre o jogar. Tese de Doutorado. Programa de Pós-Graduação em Estudos Linguísticos e Literários em Inglês (USP), 2019.

FONTANILLE, Jacques; ZILBERBERG, Claude. Tensão e significação. São Paulo: Discurso Editorial: Humanitas /FFLCH/USP, 2001.

FONTANILLE, Jacques. Pratiques sémiotiques. Paris: Presses Universitaires de France, 2008a.

FONTANILLE, Jacques. Práticas semióticas: imanência e pertinência, eficiência e otimização. In: DINIZ, Maria Lúcia Vissotto Paiva; PORTELA, Jean Cristtus (orgs.) Semiótica e mídia: textos, práticas, estratégias. Bauru: UNESP/FAAC, 2008b, p.15-74. FONTANILLE, Jacques. "L'analyse des pratiques : le cours du sens”. Protée, v. 38, n. 2 , 2010, p. 9-19. Disponível em: https://doi.org/10.7202/044947ar, acesso em 20/03/2021. FONTANILLE, Jacques. Corpo e sentido. Londrina: Eduel, 2016.

GREIMAS, Algirdas Julien; COURTÉS, Jospeh. Dicionário de semiótica. $2^{\mathrm{a}}$ ed. São Paulo: Contexto, 2013.

JUUL, Jasper. Half-Real: videogame between real rules and fictional worlds. Cambridge: MIT Press Books, 2005.

LANDOWSKI, Eric. Interações arriscadas. São Paulo: Estação das Letras e Cores, 2014. MERLEAU-PONTY, Maurice. A união da alma e do corpo em Malebranche, Biran e Bergson. Belo Horizonte: Autêntica Editora, 2016.

NASCIMENTO, Edna Maria Fernandes dos Santos. Formas de vida, acontecimento e semiótica das culturas: de Greimas a Zilberberg. In: NASCIMENTO, Edna Maria Fernandes dos Santos; ABRIATA, Vera Lúcia Rodella. Formas de vida: rotina e acontecimento. Ribeirão Preto: Coruja, 2014. p.35-54.

SOUZA JÚNIOR, Paulo Cesar. de. A interatividade no jogo eletrônico: Shadow of the Colossus. Estudos semióticos, v. 5, n. 2, 2009, p. 52-59. Disponível em: http://www.revistas.usp.br/esse/article/view/49247/53329, acesso em: 01/08/2017.

SOUZA JÚNIOR, Paulo Cesar. Entre jogador e leitor: análise semiótica da adaptação de Assassin's Creed para romance. Dissertação de Mestrado. Programa de Pós-graduação em Estudos de Linguagem (UFF), 2015.

SOUZA JUNIOR, Paulo Cesar de; MANCINI, Renata. O que a análise semiótica de um jogo do Mario tem a dizer sobre a interatividade nos videogames. Artefactum - revista de estudos em linguagem e tecnologia, v.7, n. 1, 2015. Disponível em: 
Percursos Linguísticos • Vitória (Es) •v. $11 ・ n .28$ • 2021 • ISSN: 2236-2592

http://artefactum.rafrom.com.br/index.php/artefactum/article/view/644, acesso em: 18/07/2018.

SUPER Mario world. Desenvolvimento de Nintendo Entertainment. Publicação de Nintendo. [1 console Super NES Classic], 1990. 